\title{
LUBRICATION WITH THIN GOLD FILMS
}

\author{
M. Antler* and T. Spalvins** \\ *AT\&T Bell Laboratories, Columbus, $\mathrm{OH} 43213$ \\ ** National Aeronautics and Space Administration, Lewis Research Center, \\ Cleveland $\mathrm{OH} 44135$
}

Gold Lubricants Come of Age in Aerospace Bearing and Electronic Contact Applications

\section{Introduction}

When surfaces in contact slide or roll on one another, marked adhesion and transfer of material may occur with resulting high wear or possible seizure. It is therefore necessary to interpose a lubricating film between the surfaces in order to reduce friction and wear and thereby extend the life of the device. The tribological performance and reliability requirements have increased dramatically with the development of modern space transportation systems and other equipment such as communications satellites. In many spacecraft mechanisms it is often impossible to use conventional oil and grease lubricants because of limitations in their usable temperature range, because of loss by volatilization, and because of their degradation due to radiation. Since gold is inert, has a relatively high melting point, resists radiation, and in thin layers is easily sheared, it is finding increasing use in mechanical components such as bearings gears, and splines.

Gold coatings are also essential for the sliding or wiping electric contacts of low voltage, low current devices like electronic connectors, instrument slip rings, and switches. The nobility of gold and its high conductivity have made it the preferred contact finish. Base metals are seldom used in these applications for they oxidize, tarnish, or corrode which makes it difficult to maintain the low and stable contact resistance that is necessary for reliable performance.

For both mechanical and electrical sliding applications the gold film has to satisfy two requirements:

1) adhere strongly to the surface, and

2) posses a low shear strength, thus ensuring relatively low friction.

In the development of metallic thin-film lubricants, it is essential to understand the interrelationships between film formation, morphological growth, and their resultant tribological properties. This requires detailed structural and chemical characterization at the nano-micro-macro level in order to be able to relate the tribology to adhesion, interface formation, microstructural growth changes, film thickness, and the topography of the substrate. Therefore, the objective of this paper is briefly to describe and illustrate the parameters of thin gold films which influence their lubricating properties for both bearing and electrical contact applications.

\section{Principles of metallic film lubrication}

When two touching surfaces are in a relative motion, or tribo-contact, what happens depends on the characteristics of the materials, the environmental conditions, and the nature of the contact itself. Friction originates in the deformation and shearing of surface asperities [1,2]. Adhesive wear occurs when both the surface and subsurface interact. According to the adhesion theory of friction the frictional force, $F$, is determined by the shear strength, $s$, and the real area of contact, $A$, namely $F=A s$, as shown in

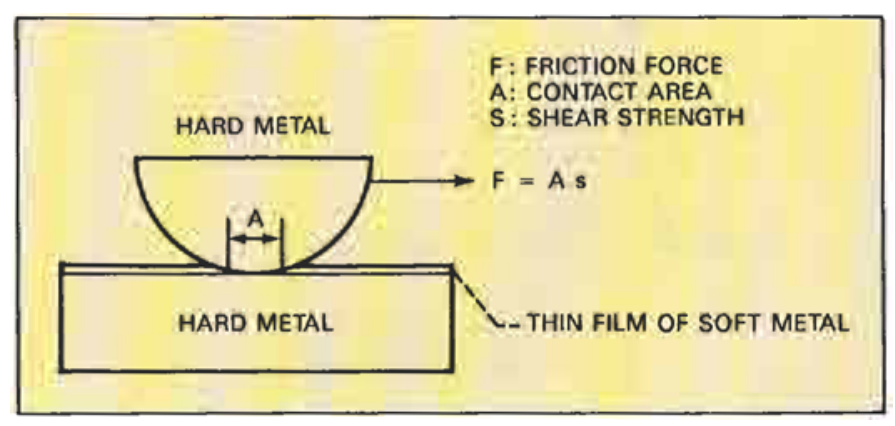

Fig. 1 The friction between metal surfaces can be lowered by depositing a thin film of a soft metal on a hard metal substrate 
Figure 1. For friction to be low, either or both $A$ and $s$ must be small. This means that the most suitable materials have high hardness and low shear strength. However, this generally is not achievable with monolithic materials; hard metals usually have high shear strengths. But by using thin layers of soft metallic films on hard, very smooth surfaces, friction and usually wear as well can be reduced. As discussed later, certain transition metal gold alloy electrodeposits are an exception; they are both relatively hard and easily sheared, and have become the predominant electrical contact materials in electronic devices.

In thin metallic film lubrication the normal load is sup-

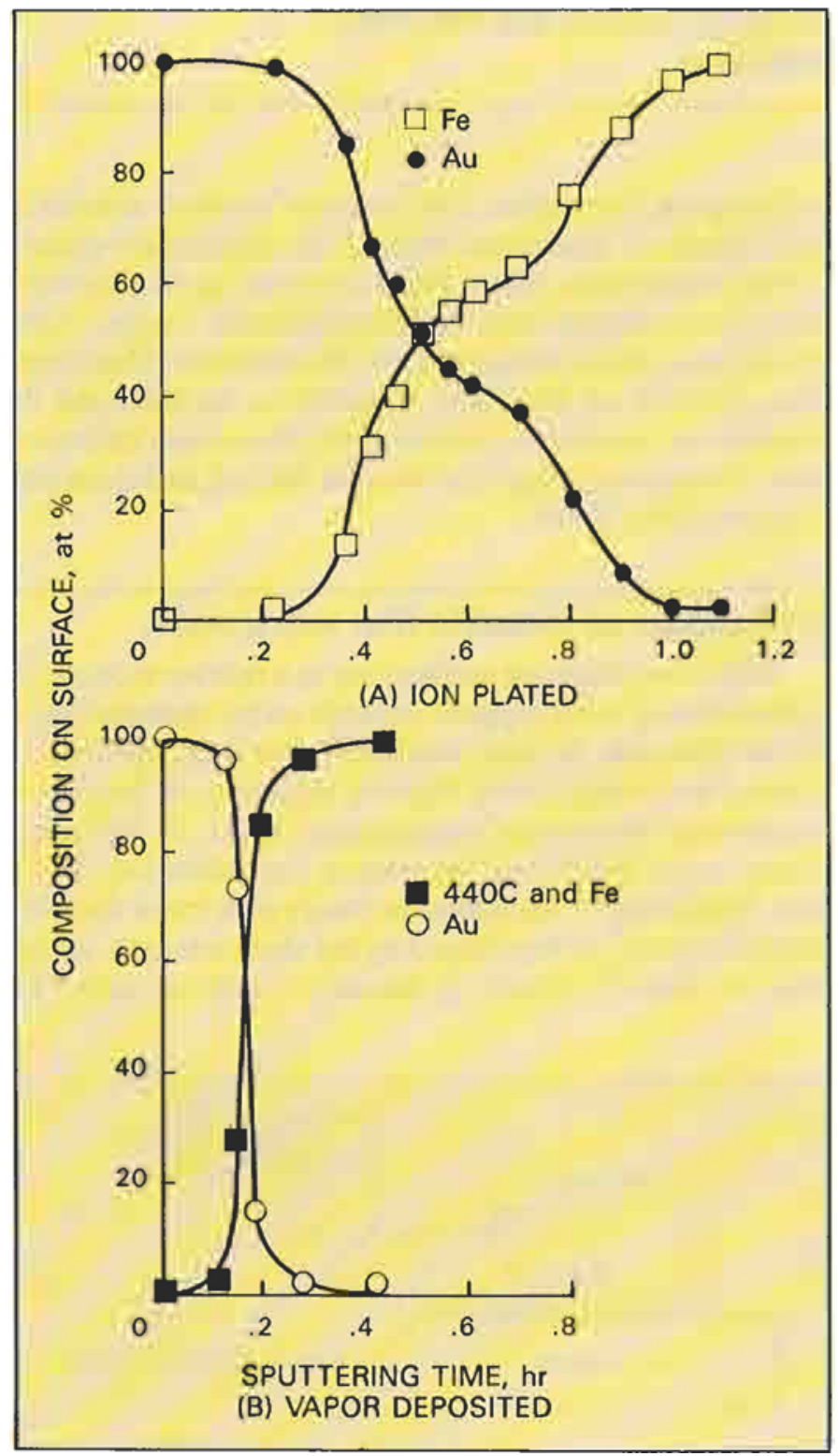

Fig. 2 Elemental depth profiles for ion-plated and vapor-deposited gold on iron ported by the contact area and friction is determined by the yield point, $p$, of the support material and shear strength of the film. The coefficient of friction, $\mu$, is a function of $s / p$. In practice a thin, easily sheared metallic film is applied to a hard substrate, and if the surfaces are brought into contact the load will be supported by the substrate. As a consequence the contact area will be relatively small. When a tangential force is imposed either in a sliding or rolling contact, shear takes place in the film.

Another requirement of metallic film lubricants is that mating surfaces be very smooth, ideally below $0.025 \mu \mathrm{m}$ r.m.s., and conform well so that the load is supported elastically, with minimal plastic deformation of the asperities. For effective lubrication, there can be no slip between the metallic film and its substrate. Thus, it must be strongly bonded so as to not be detached by the shear stresses that develop in the lubricant layer. The extent to which the coefficient of friction can be lowered depends primarily on film thickness, surface roughness, the degree of localized deformation, the mechanical properties of the film relative to those of its substrate, and the deposition technique. Some of these parameters are discussed in this paper.

\section{Coating Methodologies}

Both physical and chemical methods are used to coat surfaces with thin gold lubricant films. The physical methods involve deposition of atoms, either in vacuum or in a plasma-assisted environment, and include vapor deposition, sputtering, ion plating, and the ion implantation of gold coatings produced by other methods. The chemical methods are in aqueous media and include electroless plating and electroplating.

\section{Ion Plating}

Of the physical deposition techniques, ion plating is the preferred method. It has matured in the last decade primarily because of the demands of the aerospace industry for durable coatings which are compatible with the ferrous substrates that are the most common bearing materials.

Ion plating is conducted in a glow discharge in which ions or energetic atoms transfer energy, momentum, and charge to the substrate and the growing film in a manner which can be controlled so as to favorably modify the surface, subsurface chemistry, and microstructure. During ion plating the energizing is provided by a gas discharge which combines:

1) the impingement of ions and activated atoms of the sputtering process, 
2) the high throwing power that is characteristic of electroplating, and

3) the high deposition rates of thermal evaporation.

The impingement of the ions and neutral atoms contributes to the excellent adherence and modified structure of the film. The adherence is caused mainly by atomistic mixing which gives a graded interface, i.e., one in which there is a gradual transition between the properties of the substrate and the coating. The high throwing power provides the three-dimensional coverage that is able to coat surfaces of complex shapes. The basic ion plating system consists of a DC-diode configuration, where the specimen is made the cathode of the high-voltage circuit, with the evaporation source the anode. The principles and operation of the process have been described in the literature [3-5].

The grains in ion-plated gold films with a graded interface characteristically are small, uniform and rounded, with a high packing density and minimum lattice misfit. They are, therefore, relatively free of porosity. Furthermore, continuous films can be obtained at a thickness, as low as $0.025 \mu \mathrm{m}$. The features of ion-plated gold will be described in further detail.

\section{Adherence and Graded Interface}

In the case of films produced by conventional means, there is an abrupt transition in the structure and composition of the layer and substrate. This is reflected as a sharp difference in the coefficients of thermal expansion, the thermal conductivities, and the hardnesses. Ion plating reduces or eliminates this disparity since the interface is graded. This can be shown from an analysis of ion-plated gold films on iron surfaces by using X-ray Photoelectron Spectro-scopy (XPS) depth profiling, as in Figure 2a [6, 7]. The compositions (atomic percent) were obtained as functions of the sputter removal time. The surface composition did not change during the first 20 Fig. 3 Hardness - depth profiles for ion-plated and vapor-deposited gold on nickel substrate. Hardness measurminutes of sputtering, and ing load $0.1 \mathrm{~N}$

thereafter gradually decreased in gold content with time, during which the iron level grew. The graded interface was approximately $1.5 \mu \mathrm{m}$. On the other hand, XPS depth profiles for vacuum-deposited gold on iron or steel are shown in Figure $2 \mathrm{~b}$, where the gold content rapidly decreased with sputtering time, a characteristic of an abrupt interface.

The interface formation on nickel substrates was also investigated by making (Vickers) microhardnesss measurements. The hardness of the ion-plated gold film, graded gold-nickel interface and nickel substrate as a function of distance from the surface is shown in Figure 3a. The gold was gradually removed by argon-ion sputtering prior to the microhardness determinations. Initially, the hardness of the gold film was relatively low, but gradually increased in the interface region and finally decreased again as it reached the nickel substrate. The higher hardness in the interface region is due to alloying. The-vapor deposited gold film on nickel shown in Figure 3 b exhibited a constant hardness, which is indicative of a sharp interface.

It is therefore clear why ion-plated films with a gradedfused interface adhere so well. The surface strengthening is an additional bonus of the coating process since it im-

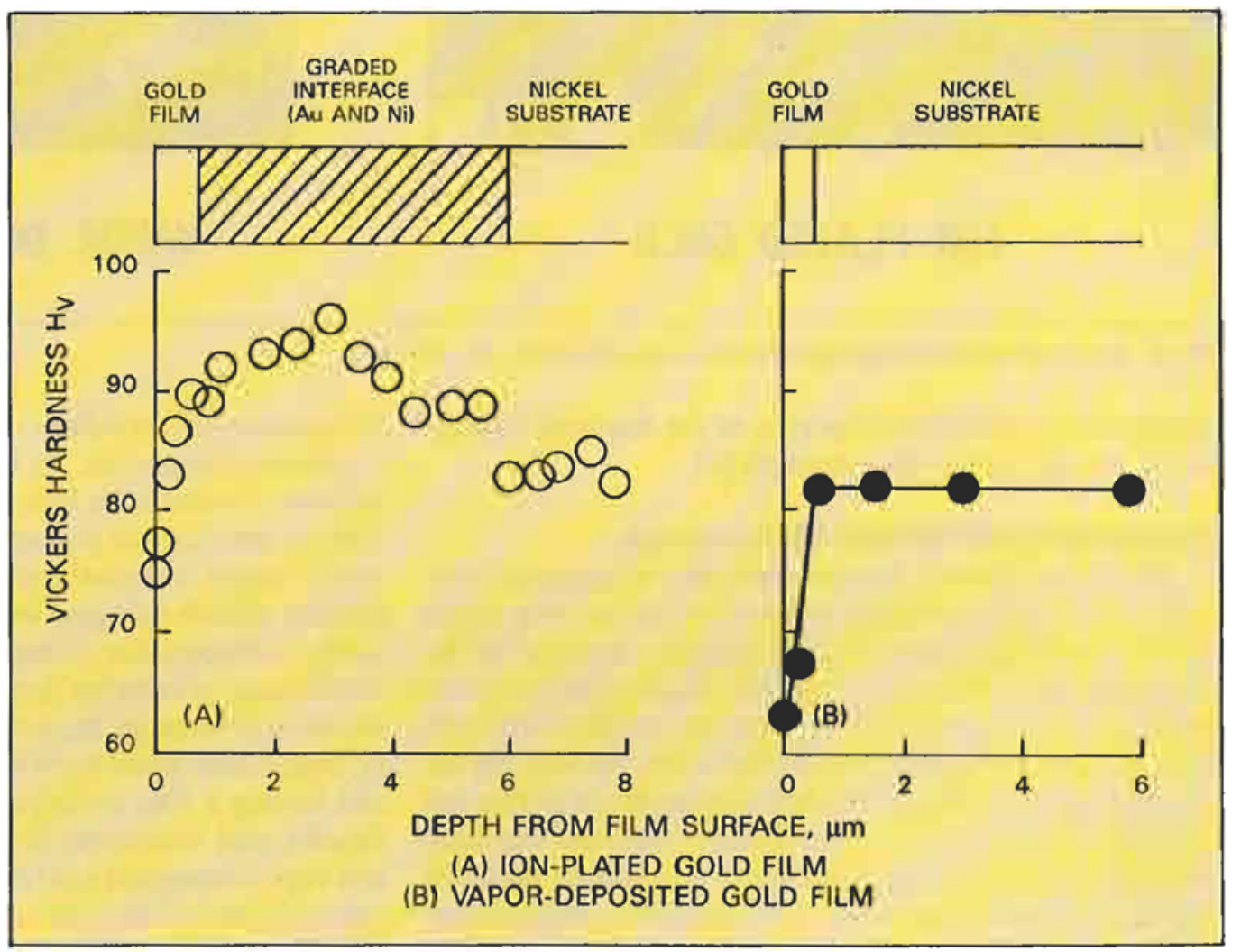




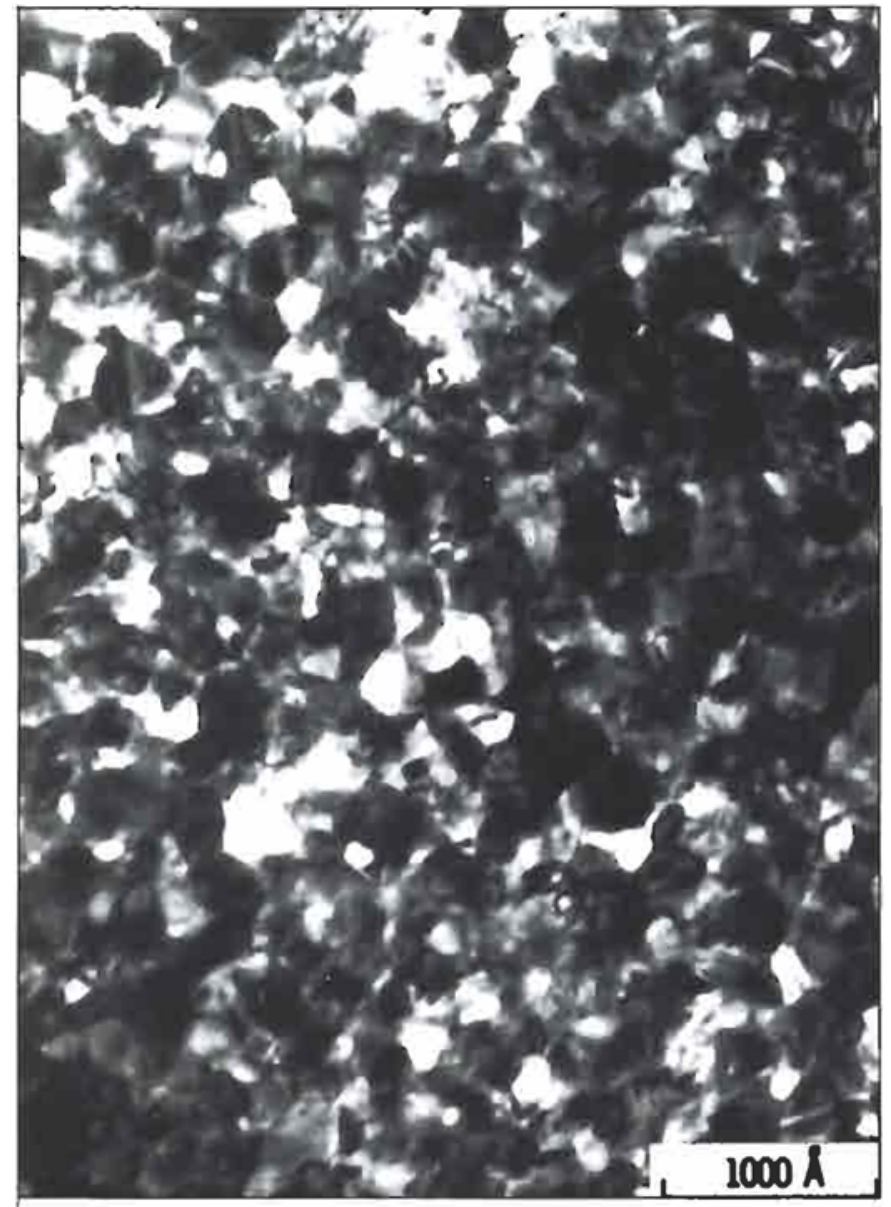

ION PLATED GOLD

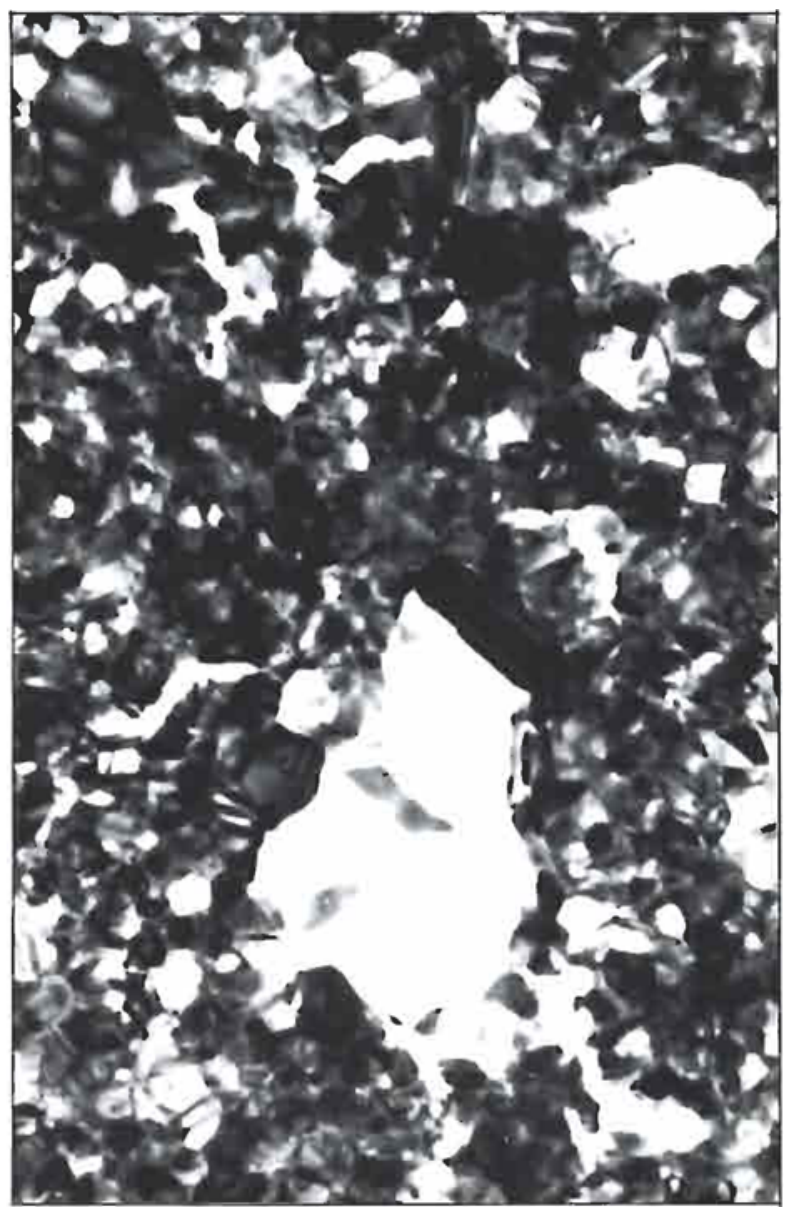

VAPOR DEPOSITED GOLD

Fig. 4 Transmission electron micrograph of the crystal structure of a gold film

proves the mechanical properties of the material, such as yield, tensile, and fatigue strength [8].

\section{Nucleation and Growth Morphology}

During ion plating the evaporent flux of energetic ions and atoms transfers energy, momentum, and charge to the substrate and the deposited film surface. Because of the low ionization efficiency of the DC-diode process, atoms arrive at the substrate with a range of energies. The high energy particles implant into the substrate without diffusing over the surface. Continuous bombardment during ion plating sputters loosely bonded atoms from the substrate surface, thus leaving high-energy implanted particles which act as nucleation sites. Ion plated films, unlike those from conventional vapor deposition, exhibit a nucleation behavior with several distinct characteristics. The nuclei are considerably smaller $(150 \AA)$, have a high density, and a uniform distribution. As deposition continues the nuclei remain rounded with less than a 20 per cent increase in size. In the classical process there is a decreasing tendency for nuclei to remain round after coalescence; consequently islands elongate and join to form an irregular network. As deposition continues in ion plating, the existing nuclei grow somewhat, but formation of new nuclei continues to be a major growth mechanism [9]. Consequently, continuous films form with nuclei about $250 \AA$ in size and having a fine uniform grain structure, high packing density, and minimum lattice misfit. Typical ion-plated and vapor-deposited gold films are shown in Figure 4. The vapor-deposited film has a highly non-uniform grain size and shape. 


\section{Electrodeposition}

There are several chemical methods for applying gold films to substrates including immersion plating, [10] electroless deposition, [11] and electroplating. Of these, electroplating procedures are the most developed and nearly all gold coated electronic contacts are produced by this method. The literature on electroplating chemistry, plating process equipment, bath maintenance and control, and the properties of electrodeposits is vast, as would be expected for a technology that was born over 100 years ago.

Electrodeposition methods are used to coat several million troy ounces of gold a year worldwide, the bulk of it in electronic applications, and most of the latter for electric contacts [12]. The advantages of electrodeposition over other chemical methods are the superior properties of the coatings and its relatively low cost. Immersion deposits are porous, limited in thickness, and difficult to control, particularly in purity. Electroless plating involves solutions that contain a gold electrolyte, such as AuCN, and a reducing agent, like $\mathrm{KBH}_{4}$. Electroless methods are autocatalytic in that they do not require an external current. Their plating rate is, however, slow, the processes are difficult to control, and the chemicals are considerably more costly than those used in electroplating.

The explosive growth of the electronics industry since 1950 was the incentive for the development of electroplating process technology, particularly high-speed continuous, automated, reel-to-reel equipments that can goldcoat millions of contacts a day for only a fraction of a cent (US\$0.01) each including the cost of the precious metal. Laboratory, or 'beaker', plating methods for making small quantities of samples for trial purposes involve simple equipment, which costs only a few hundred dollars. It is not surprising, therefore, that there is little literature on the contact properties of gold coatings made by the more complex and costly physical deposition methods.

Gold electrodeposits must be adherent in order to function successfully in contact applications. In addition, they should be non-porous in thin layers when plated on the usual base-metal substrates, in order to be suitable for contacts that are used in polluted atmospheres, especially at elevated relative humidity. The possible formation of insulating corrosion products at pore sites must be prevented. These requirements can be readily met by suitable preplate substrate cleaning methods and the use of strikes of copper, nickel, or other metals [13]. The adhesion of an electrodeposit to its substrate is ordinarily so strong that the weaker of the two metals fractures when attempts are made to separate the metals; in other words, the interface between them is not broken [14].

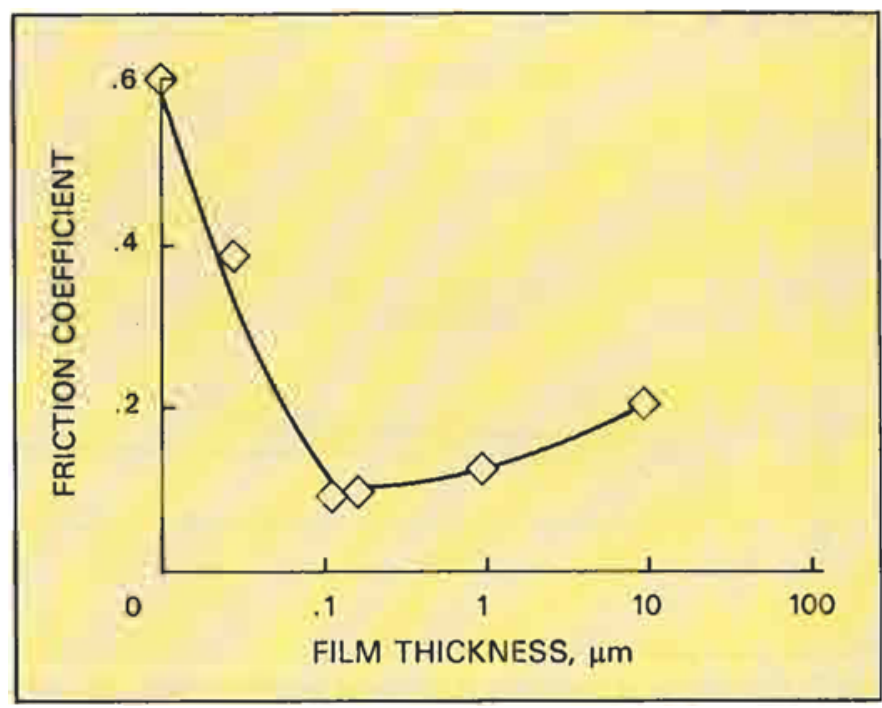

Fig. 5 The variation of friction coefficient with gold film thickness (load $2.45 \mathrm{~N}$; speed $1.52 \mathrm{~m} \mathrm{~min}^{-1}$; pressure $2 \times 10-3$ torr; roughness $0.02 \mu \mathrm{m}$ r.m.s.)

\section{Gold in Aerospace Applications}

Most metallic-film lubricants, such as lead, tin, silver, and indium, have low melting points and are not resistant to oxidation. However, pure gold is an exception since it is chemically inert and has a relatively high melting point. Thin gold films are therefore one of the most promising lubricants in high-temperature, high-vacuum, and radiation environments. For instance, the reasons for selecting a gold film in aerospace applications are:

1) its long-term stability with no tendency to contaminate adjacent surfaces by degassing or evaporation,

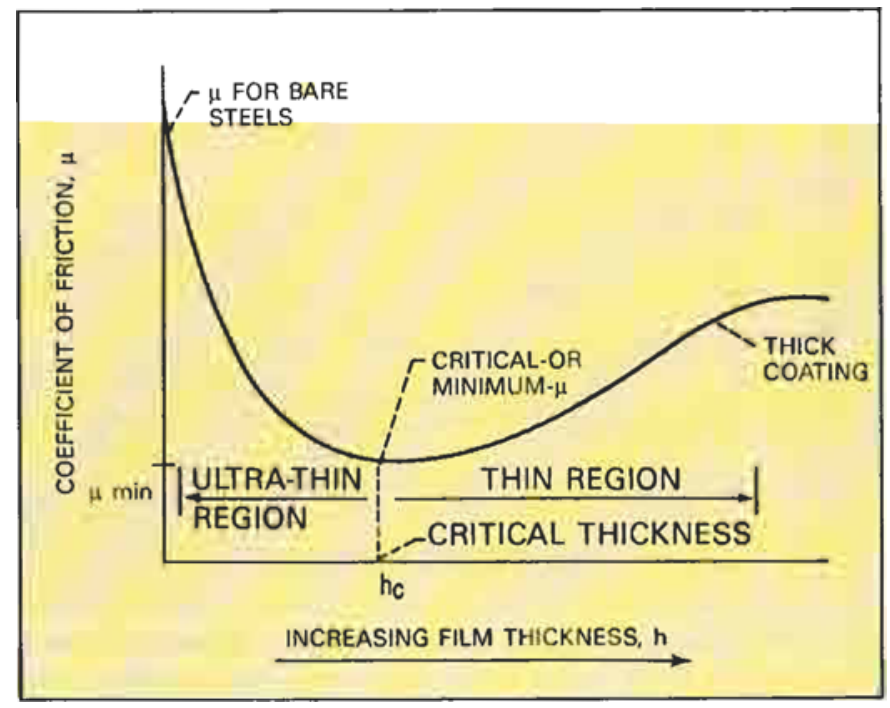

Fig. 6 Schematic representation of the effect of film thickness on the friction coefficient of low shear-strength metallic films on steel 


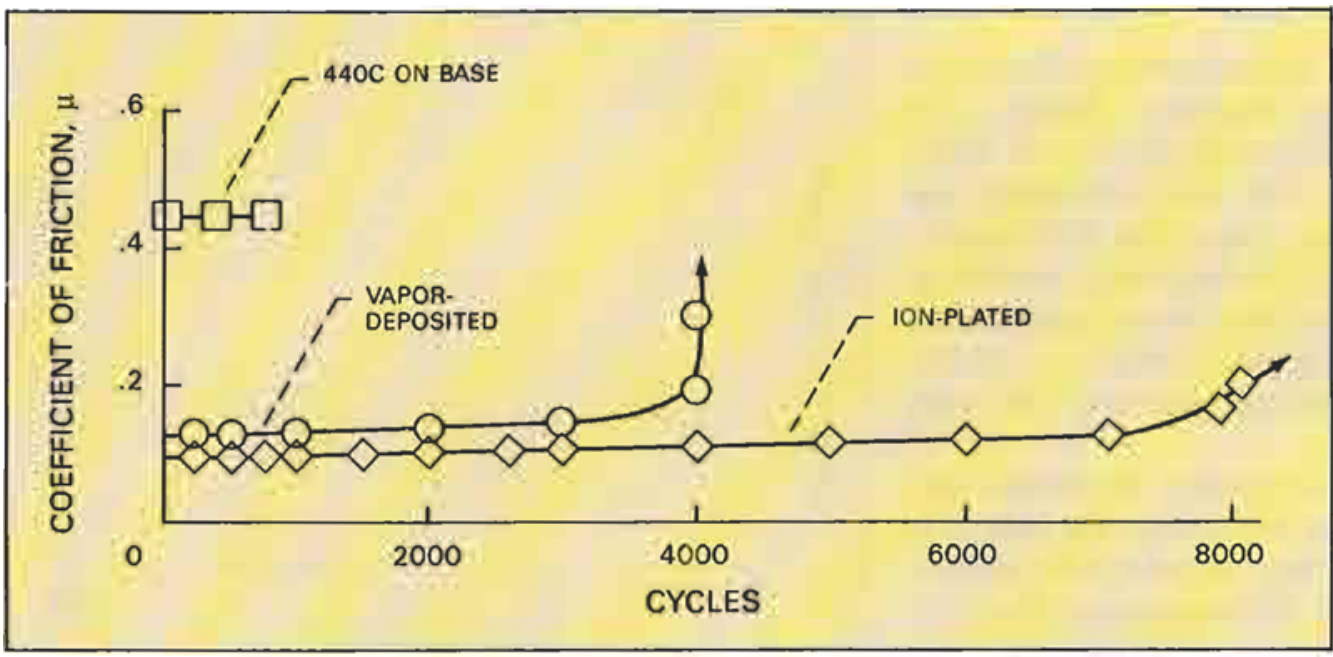

Fig. 7 Comparison of coefficient of friction of ion plated and vapor- deposited gold films on 440C steel

2) frictional properties that are influenced little by changes in temperature or by shear rate, and

3) low torque noise and vibration levels over the duration of the mission.

\section{Film Thickness versus Friction}

In determining the requirements for using gold as a thin film lubricant, a number of variables were explored. One of these was the effect of thickness of the gold on sliding friction. It was found that the gold thickness had a very pronounced effect, as shown in Figure 5 in a study using a $440 \mathrm{C}$ stainless steel hemisphere sliding on gold-coated $440 \mathrm{C}$ steel. At a gold thickness of about 2000 to $3000 \AA$,

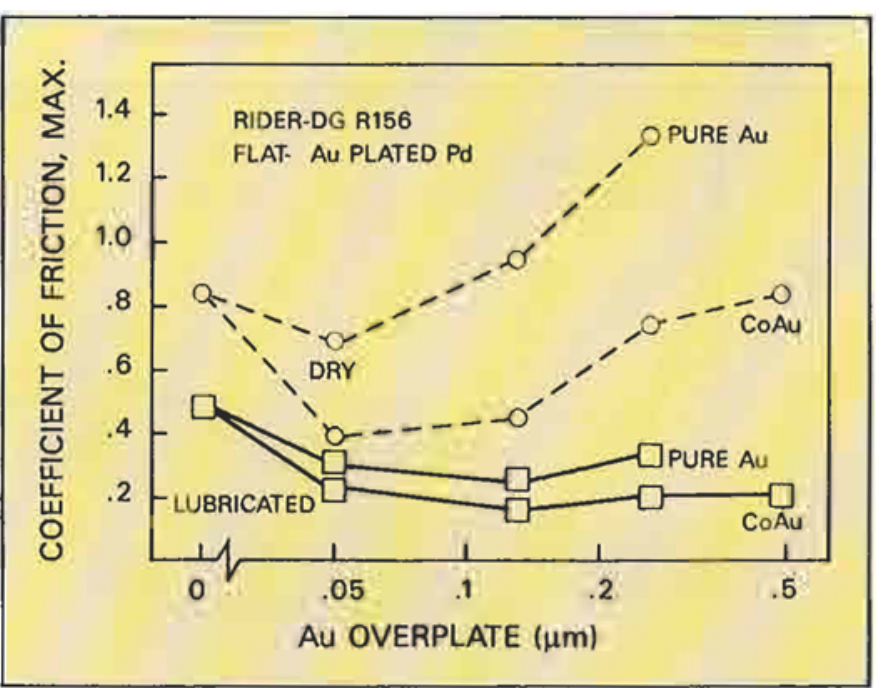

Fig. 8 Relationship between the maximum values coefficient of friction in runs with DG R-156 coated riders versus gold- and palladium-plated coupons (having a nickel subplate). The variables were the type of gold plate (either pure or cobalt-hardened) and its thickness, and whether the flat were dry or were lubricated with a thin layer of a polyphenylether fluid the coefficient of friction was at a minimum of 0.1 [15]. When the deposited layer was excessively thick there was no reduction in friction since both the junction shear strength and the yield point are determined strictly by the properties of the soft gold. At the optimum thickness, the shear strength is that of the gold film while the contact surface and the yield point are determined by the properties of the hard support material.

Based on these results and those of many similar experiments, the variation of friction with film thickness can schematically be divided into two regions, as shown in Figure 6. Below the critical film thickness, where friction is at a minimum, there is steel-to-steel contact. At film thicknesses greater than the critical value an increasing proportion of the load is carried by the metallic film, thus progressively reducing the effect of the hard substrate. The critical film thickness for lowest friction is affected by surface roughness. Best results are obtained when substrate surface roughness is less than $0.05 \mu \mathrm{m}$ r.m.s. With rough surfaces the friction coefficient increases continuously as the film thickness increases without going through a minimum $[16,17]$.

\section{Frictional Characteristics and Applications}

The ion-plated gold films always show better tribological performance than vapor-deposited films, and therefore they have found extensive use in precision bearings, gimbals, gears and splines of space satellite mechanisms. Typical friction curves for ion plated and vapor deposited gold films $2000 \AA$ thick, as determined in a pin-and-disk tribotester under vacuum conditions, are shown in Figure 7. The ion-plated gold films had three distinct advantages over the vapor- deposited ones:

1) an increased life,

2) a lower coefficient of friction, and

3) the avoidance of catastrophic failure.

The reasons for the increased endurance are the superior adherence; the lower coefficient of friction due to the dense, cohesive, small crystallite size and the optimum film thickness; and the gradual increase in the coefficient of friction after the film has been worn off to a graded interface. 


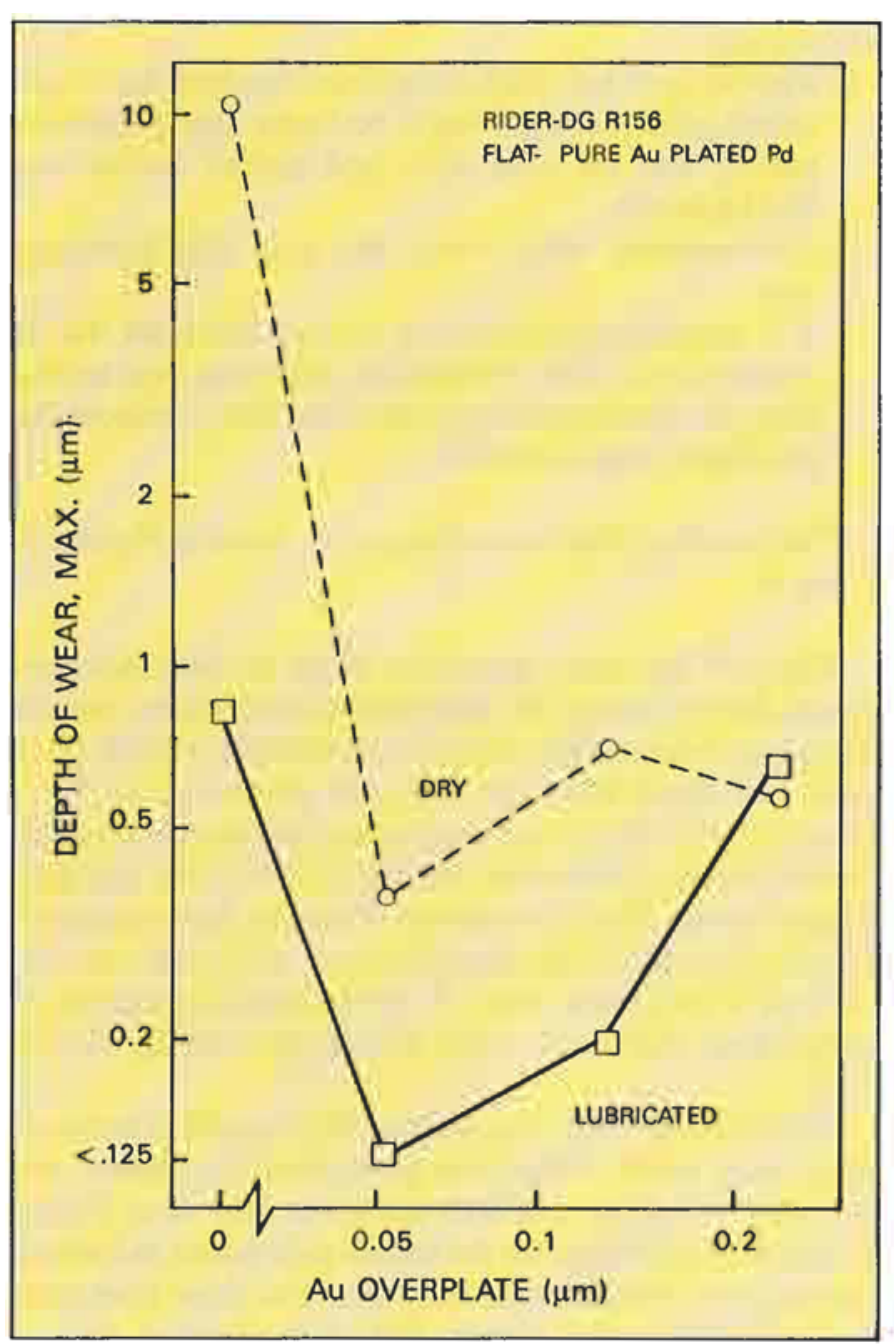

Fig. 9 Wear of flats having $1.5 \mu \mathrm{m}$ of palladium plate on $1.25 \mu \mathrm{m}$ of nickel from dry and lubricated sliding against DG R-156 riders. Thickness of the pure gold overplatings on flats was varied from 0 to $0.25 \mu \mathrm{m}$. Wear is expressed as the depth of the deepest scratch from three parallel traversals across the track using a profilometer

\section{Gold in Electrical Contacts}

Gold is the material of first choice for electric contacts because of its low contact resistance and its nobility. Low friction is essential in many applications because only small motive forces are available (instrument slip rings) or because the numbers of contacts which are involved is very large, as in connectors having hundreds of contact pairs that engage simultaneously in an insertion. Wearthrough of the precious metal coating is undesirable since the substrate is usually a base metal.

It is not surprising, therefore, that gold has become the dominant material for high reliability devices. At thick-

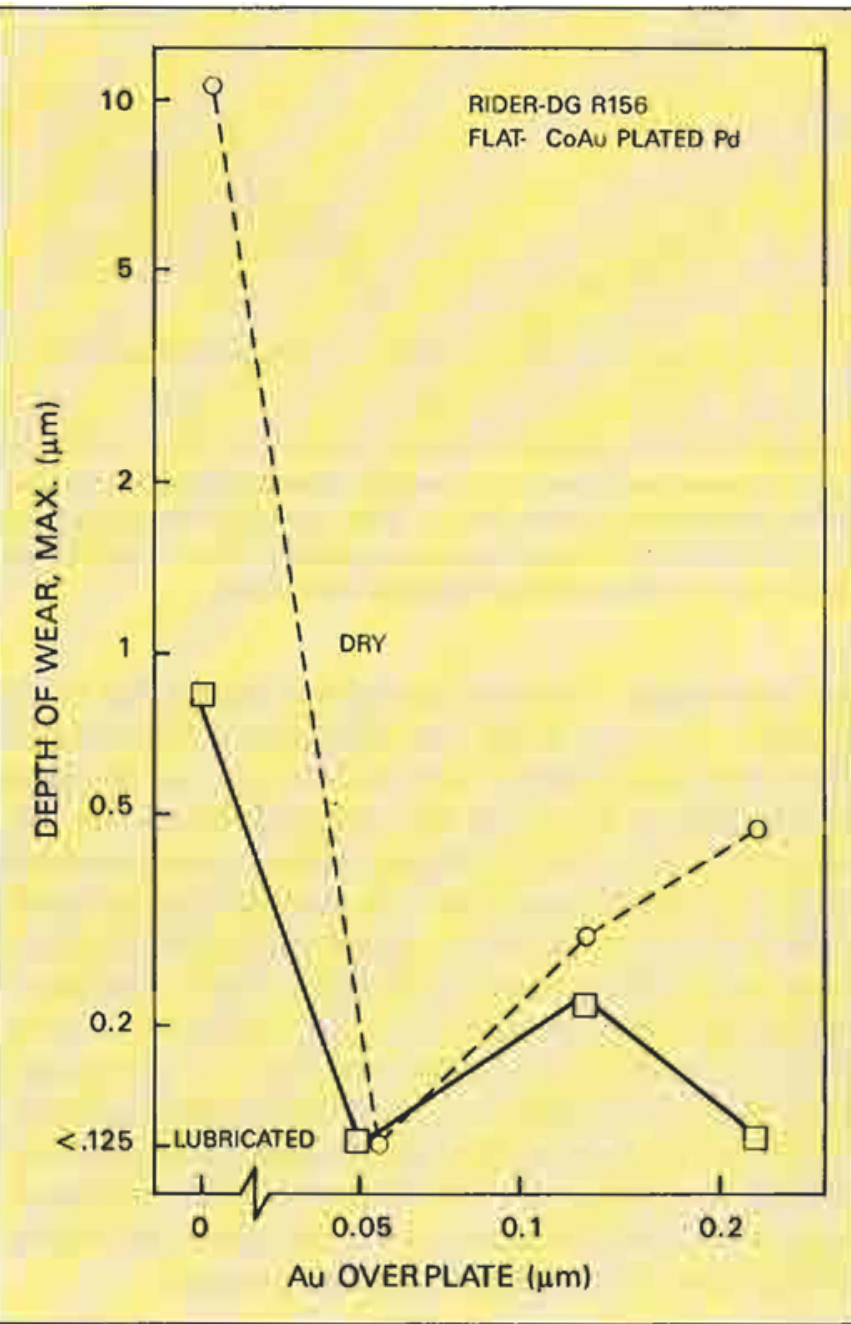

Fig. 10 Wear of palladium plated flats from dry and lubricated sliding against DG R-156 riders, The palladium platings were overplated with various thickness of cobalt-gold. These experiments were similar to those in Fig. 9 in which pure gold overplatings were used. Note that the maximum depth of the wear tracks was equal to or less with cobalt-gold than when pure gold was used

nesses in the range of 0.5 to $5 \mu \mathrm{m}$, depending on the application, it is in general highly satisfactory, and the bulk characteristics of the deposit control its properties, including friction and wear. However, with the escalation since 1972 in the cost of gold, intensive research into methods for limiting its use were initiated in many industrial laboratories. A significant achievement has been the development of methods for selectively depositing the gold on the functional surface only, i.e., that part of the contact member (such as a cantilever spring or a socket formed from a sheet copper alloy) that actually makes physical contact with its opposing member. An equally important development was the identification of less expen- 


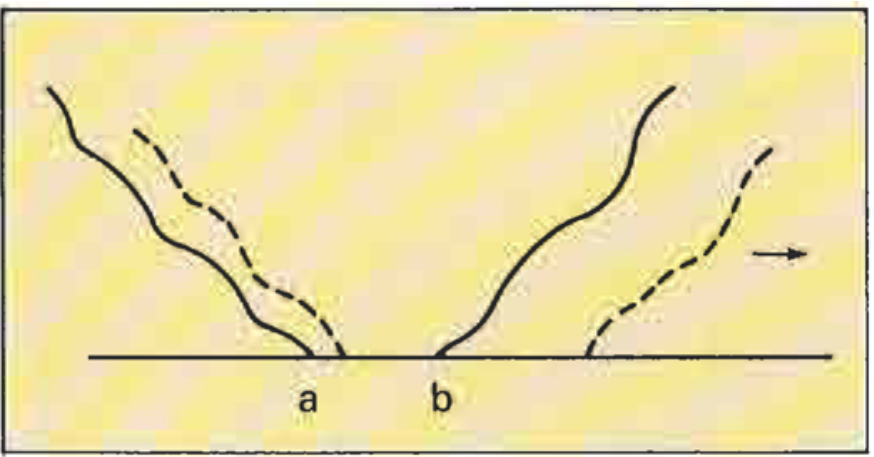

Fig.11 Schematic representation of junction growth. Normal load deforms asperity so that contact occurs along ab. When a tangential stress is imposed in the direction of the arrow, the junction grows, as shown by the dashed lines, and the two members approach each other slightly

sive semi-noble or passive underlying metals that could substitute for most of the gold thickness, and the use of thin coatings $(0.05$ to $0.25 \mu \mathrm{m}$ thick) of gold as top layers for the purpose of giving the composite finish the corrosion resistance and tribological performance of a much thicker gold when used alone. The properties of thin goldcoated palladium, palladium-nickel and palladium-silver alloys, ruthenium, and nickel alloyed with tin or with phosphorus, have been described [18-23]. Nearly all of these underlying metals are themselves made by continuous electrodeposition methods which involve numerous steps, from an initial degreasing of the substrate through a final washing and drying. By far, the most popular composite material is a flash gold coating on 0.5 to $2 \mu \mathrm{m}$ of palladium, usually on an electrodeposited nickel subplate.

\section{Friction and Wear versus Film Thickness}

The sliding properties of electroplated palladium and of most solid noble contact metals are poor; they are prone to severe adhesive wear and high friction. A thin film of gold on one or both contact surfaces can significantly improve performance. Just as with ion-plated aerospace bearings, the improvement may be critically dependent on the thickness of the gold layer. This is illustrated in the following study with a rider-on-flat tribotester under experimental conditions that simulated the contacts in a pinsocket electronic connector [24]. The finish of the pin (the flat in the tribotester) was electroplated palladium which wore poorly, with high friction, against the socket spring contact (the rider). The latter was made of DG R-156, a clad palladium-silver alloy having a gold-rich surface produced by a controlled diffusion treatment [25].

The potential value of coating the palladium with an easily sheared thin gold film was recognized from other contact systems in which gold-on-palladium contacts were successfully mated to themselves [18]. What was not known was:

1) whether pure soft gold or the much harder 0.2 per cent cobalt-gold platings would be better (the palladium plating and the clad alloy had similar hardnesses, $250 \mathrm{~kg} / \mathrm{mm}^{2}$ ),

2) how behavior would vary with gold film thickness, and,

3) if a supplementary organic contact lubricant that is commonly used in commercial connectors was necessary, or whether this fluid lubricant alone, without the gold layer, would suffice.

The results of this investigation are given in Figures 8 , 9 and 10.

Figure 8 illustrates the results of the friction measurements. In dry sliding, the unlubricated palladium contacts had a maximum coefficient of friction of 0.8 in a 200 -cycle test. The fluid lubricant lowered this value to 0.45 . However, the dry cobalt-gold coated palladium was still better, having a minimum value of 0.38 at a $0.05 \mu \mathrm{m}$ gold film thickness. The combination of a thin cobalt-gold coating plus the additional layer of oil was best, with a coefficient of friction that was 0.2 or less and independent of cobalt-gold thickness within the range studied, 0.05 to $5 \mu \mathrm{m}$.

Figure 9 illustrates the wear of this system in terms of the scratch depth of the pure gold plated palladium contact. A film thickness of $0.05 \mu \mathrm{m}$ gives least wear. Figure 10 shows similar data for the cobalt-gold plated palladium system; the overall results are superior to those from pure gold (Figure 9) and closely follow the friction data of Figure 8 . The shape of the friction curves is similar to that in Figure 6 which was developed for ion plated gold.

The superior effectiveness of the cobalt-doped gold film compared to that of the pure gold seems anomalous, since the former is considerably harder. However, this can be readily explained by considering the ductility of the two golds. Cobalt-gold electroplate is relatively brittle, having an elongation of about 0.5 per cent [22] and resists the marked asperity junction growth of pure electrodeposited gold, which is at least an order of magnitude more ductile [26]. Junction growth theory is illustrated [27] in Figure 11. Electrodeposited cobalt-gold, which is both hard and brittle, shears easily and is the preferred thin film coating for electronic contacts. It also is superior to pure gold when used in relatively thick layers on the substrate contact material.

The brittleness of cobalt-gold has been attributed [22] to its intrinsic codeposited polymers. These metal-organic substances occur mainly as particles about $25 \AA$ in size $[28,29]$, although there is evidence that some particles 
may be larger [30]. These particles probably block the movement of dislocations when the metal is deformed and in this way are responsible for lowering the ductility of the deposits. Electrodeposited golds that contain other transition metals, such as nickel and iron usually in the range of 0.05 to 1 per cent, are also brittle and have been found to contain codeposited polymers. The polymers originate in complex electrochemical reactions and come from the gold cyanide ions in the plating solutions. Pure electrodeposited golds are polymerfree even when obtained from cyanide systems.

The lubricating ability of the thin gold film would be expected to diminish with increasing substrate roughness, as described earlier in connection with aerospace bearings. This was not investigated because it has long been considered good practice to use substrates that are as smooth as is economically practical to obtain. The intrinsic porosity of electrodeposits is directly related to roughness [31]. The contacts of this study had a value of $0.05 \mu \mathrm{m}$ r.m.s., which is usual for stamped formed substrate produced from strip coil material - a phosphor bronze, brass, or copper beryllium alloy.

\section{Typical Electrodeposited Gold Contact}

A pin contact in large scale production having a finish that consists of a flash coating of cobalt-gold on electroplated palladium is illustrated in Figure 12. The noble metals are selectively deposited on the end of the pin and a socket is shown in the mated position. The pins are pressed into plated-through holes of a printed current board backplane where they make electrical contact with the copper conductors of the board. The back ends of the pins are joined to conductors or other connectors by a variety of termination techniques. Individual backplanes are made with thousand of these pins, and the connectors have as many as several hundred sockets, depending on the application. A low-friction contact finish is necessary, for the connection is made by hand.

\section{Conclusions}

Sliding, rolling, and wiping surfaces in applications as diverse as aerospace ball-bearings and separable electronic connectors are being made with thin gold coatings that serve as effective lubricants. In metal film lubrication, the thin gold layer is easily sheared when subjected to a tangential stress which reduces friction and wear, while the harder substrate supports the load. Although some other metals can also perform this function, it is a combination of various characteristics which makes gold unique and therefore the preferred coating. These include its high conductivity and especially its chemical inertness which preclude the formation of insulating tarnish and corrosion products - an essential requirement for electrical contacts.

For aerospace applications, in addition to gold's inertness, its high melting point, non-volatility, relatively constant properties over a wide temperature range, and radiation stability make it more desirable than the alternative grease and oil lubricants. The requirements for smooth substrate and the range of gold thickness for greatest effectiveness (about $0.05-0.1 \mu \mathrm{m}$ ), are similar in these applications although different coating processes are preferred. In the aerospace industry, ion-plated films provide a graded interface and the best adhesion to the usual ferrous substrates which, in turn, assure a long service life.

In electric contacts, electrodeposits are preferred be- 
cause of their low cost and the suitability of their processes for high rates of production. Also, golds that are doped with cobalt are generally superior in electric contacts, while pure gold is standard in the aerospace field.

\section{References}

1 F.P. Bwoden and D. Tabor, Friction and Lubrication of Solids, part I, Clarendon Press, Oxford, 1950, 111-21

2 D.H. Buckly, Surface Effects in Adhesion, Friction, Wear and Lubrication, Tribology Series 5, Elsevier, 1981, 324-337

3 D.M. Mattox, 'Ion Plating Technology', Deposition Technologies for Films and Coatings, (ed., R.F. Bunshah), Noyes Publications, Park Ridge, IL, 1982, 244-87

4 D.M. Mattox, 'Mechanisms of Ion Plating', Proceedings of the International Conference on Ion Plating and Allied Techniques, IPAT 79, CEP Consultants Ltd., Edinburgh, England, 1979, 1-10

5 T. Spalvins, 'Survey of Ion Plating Sources', J. Vac. Sci. Technol., 1980, 17, 315-21

6 K. Miyoshi, T. Spalvins and D.H. Buckly, 'The X-Ray Photoelectron Spectroscopy Depth Profiling and Tribological Characterization of Ion-Plated Gold on Various Metals', Thin Solid Films, 1983, 108, 199-207

7 K. Miyoshi, T. Spalvins and D.H. Buckley, 'Tribological Characteristics of Gold Films Deposited on Metals by Ion Plating and Vapor Deposition', 3rd Int. Conf. on. Solid Lubrication, ASLE SF-14, ASLE, Park Ridge, IL, 1984, 208-16

8 T. Spalvins, 'Coatings for Wear and Lubrication, Thin Solid Films, 1978, 53, 285-300

9 G.S.A. Shawki, M.G. El-Sherbiny and F.B. Salem, 'Nucleation and Interface Formation in Thin Films', Thin Solid Films, 1981, 75, 29-36

10 F.H. Reid and W. Goldie, Gold Plating Technology, Eds., Electrochemical Publications Ltd., Ayr, Scotland, 1974 , chapter by E.A. Parker on 'Immersion Solutions', 73-82

11 F.H. Reid and W. Goldie, Gold Plating Technology, Eds., Electrochemical Publications Ltd., Ayr, Scotland, 1974, chapter by Y. Okinada on 'Electroless Solutions', 82-104

12 Gold/1987, Consolidated Gold Fields, New York, NY

13 F.H. Reid and W. Goldie, Gold Plating Technology, Eds., Electrochemical Publications Ltd., Ayr, Scotland, 1974, chapter by W.K.A. Congreve on 'Pretreatment and Plating Procedures', 105-142

14 F.H. Reid and W. Goldie, Gold Plating Technology, Eds., Electrochemical Publications Ltd., Ayr, Scotland, 1974, chapter by F.H. Reid on 'Measurement of Adhesion', 422-429

15 T. Spalvins and B. Buzek, 'Frictional and Morphological Characteristics of Ion-Plated Soft Metallic Films', Thin Solid Films, 1981, 84, 267-72

16 R.D. Arnell and F.A. Soliman, 'The Effects of Speed, Film
Thickness and Substrate Surface Roughness on the Friction and Wear of Soft Metal Films in Ultrahigh Vacuum', Thin Solid Films, 1978, 53, 333-41

17 M.A. Sherbiny and J. Halling, 'Friction and Wear of IonPlated Soft Metallic Films', Wear, 1977, 45, 211-20

18 T. Sato, Y. Matsui, M. Ukada, K. Murakawa and Z. Henmi, 'Palladium with a Thin Gold Layer as a Sliding Contact Material', IEEE Trans. on Components, Hybrids, and Manufacturing Techn., 1981, CHMT4(1), 10-14

19 F.I. Nobel, 'Electroplated Palladium - Silver (60/40 wt.\%) Alloy as a Contact Material', IEEE Trans, on Components, Hybrids, and Manufacturing Techn., 1985 , CHMT-8(1), 163-72

20 S.W. Updegraff, 'Better than Gold; A Palladium-Nickel Coating System for High Reliability Connectors', Proc. 33rd Electronic Components Conf., IEEECHMT Soc. and EIA, Orlando, FL, 1983, 425-31

21 R.G. Baker and T.A. Palumbo, 'The Potential Role of Ruthenium for Electronic Applications', Plating and Surface Fin, 1982, 69(1), 66-68

22 M. Antler, 'Sliding Wear of Metallic Contacts', IEEE Trans. on Components, Hybrids, and Manufacturing Techn., 1981, CHMT-4(1), 15-29

23 C.A. Holden, R.L. Opila, H.H. Law and G.R. Crane, 'Wear Resistance of Nickel and Nickel Phosphorus Alloy Electrodeposits', Proc. IEEE-Holm Conference on Electrical Contacts, IEEE-CHMT Soc., San Francisco, CA, 1988

24 M. Antler and M. Feder, 'Wear and Friction of Electrodeposited Palladium Contacts: Thin Film Lubrication with Fluids and with Gold', IEEE Trans. on Components, Hybrids, and Manufacturing Te.hn. 1986, CHMT-9(4), 485-91

25 F.E. Bader, 'Diffused Gold R-156: A new Inlay Contact Material for Bell System Connectors', Proc. Int. Conf. on Electric Contact Phenomena, Verband Deutscher Elektrotechniker (VDE), West Berlin, Germany, 1982, 133-37

26 W.H. Safranek, The Properties of Electrodeposited Metals and Alloys, 2nd ed., American Electroplaters and Surface Finishers Soc., Orlando, FL, 1986, 163-94

27 F.P. Bowden and D. Tabor, The Friction and Lubrication of Solids, part II, Oxford, Clarendon Press, 1964, 56

28 Y. Okinaka, F.B. Koch, C. Wolowodiuk and D.R. Blessington, 'Polymer Inclusions in Cobalt-Hardened Electroplated Gold', J. Electrochem. Soc., 1978, 125(11), 1745-50

29 Y. Okinaka and S. Nakahara, 'Structure of Electroplated Hard Gold Observed by Transmission Electron Microscopy', J. Electrochem. Soc., 1976, 123(9), 128489

30 M. Antler, 'Structure of Polymer Codeposited in Gold Electrodeposits', Plating, 1973, 60(5), 468-74

31 S.M. Garte, 'Effect of Substrate Roughness on the Porosity of Gold Electrodeposits', Plating, 1966, 53, 1335-39 